\title{
Komparasi Metode Peramalan Jumlah Permintaan Kamar Hotel
}

\author{
Rendra Gustriansyah $^{1)}$, Wilza Nadia ${ }^{2)}$, Mitha Sofiana ${ }^{3)}$ \\ ${ }^{1223)}$ Teknik Informatika, Universitas Indo Global Mandiri, Palembang \\ Jalan Jenderal Sudirman No. 629, Palembang 30129, Indonesia \\ Email: rendra@uigm.ac.id ${ }^{1)}$ willza.nadi@gmail.com ${ }^{2)}, \underline{\text { sofianamitha31@gmail.com }{ }^{3)}}$
}

\begin{abstract}
Hotel is a type of accommodation that uses most or all of the buildings to provide lodging, dining and drinking services, and other services for the public, which are managed commercially so that each hotel will strive to optimize its functions in order to obtain maximum profits. One such effort is to have the ability to forecast the number of requests for hotel rooms in the coming period. Therefore, this study aims to forecast the number of requests for hotel rooms in the future by using five forecasting methods, namely linear regression, single moving average, double moving average, single exponential smoothing, and double exponential smoothing, as well as to compare forecasting results with these five methods so that the best forecasting method is obtained. The data used in this study is data on the number of requests for standard type rooms from January to November in 2018, which were obtained from the Bestskip hotel in Palembang. The results showed that the single exponential smoothing method was the best forecasting method for data patterns as in this study because it produced the smallest MAPE value of $41.2 \%$.
\end{abstract}

Keywords: forecasting, linier regression, moving average, exponential smoothing.

\begin{abstract}
Abstrak
Hotel merupakan jenis akomodasi yang mempergunakan sebagian besar atau seluruh bangunan untuk menyediakan jasa penginapan, makan dan minum serta jasa lainnya bagi umum, yang dikelola secara komersial, sehingga setiap hotel akan berupaya untuk mengoptimalkan fungsinya agar memperoleh keuntungan maksimum. Salah satu upaya tersebut adalah memiliki kemampuan untuk meramalkan jumlah permintaan terhadap kamar hotel pada periode mendatang. Oleh karena itu, penelitian ini bertujuan untuk meramalkan jumlah permintaan terhadap kamar hotel di masa mendatang dengan menggunakan lima metode peramalan, yaitu regresi linier, single moving average, double moving average, single exponential smoothing, dan double exponential smoothing, serta untuk mengetahui perbandingan hasil peramalan dengan kelima metode tersebut sehingga diperoleh metode peramalan terbaik. Adapun data yang digunakan dalam penelitian ini merupakan data jumlah permintaan kamar tipe standar dari bulan Januari hingga November tahun 2018, yang diperoleh dari hotel Bestskip Palembang. Hasil penelitian menunjukkan bahwa metode single exponential smoothing merupakan metode peramalan terbaik untuk pola data seperti pada penelitian ini karena menghasilkan nilai MAPE paling kecil sebesar $41.2 \%$.
\end{abstract}

Kata kunci: peramalan, regeresi linier, moving average, exponential smoothing. 


\section{Pendahuluan}

Hotel sebagai jenis akomodasi yang mempergunakan sebagian besar atau seluruh bangunan untuk menyediakan jasa penginapan, makan dan minum serta jasa lainnya bagi umum, yang dikelola secara komersial (Menteri Pariwisata 1986).

Hotel juga harus mempunyai pelayanan dan fasilitas terbaik agar dapat menarik perhatian wisatawan atau pembisnis yang ingin menginap di hotel.

Setiap hotel akan bersaing untuk memperoleh tingkat hunian sesuai dengan kelasnya masing-masing. Karena peningkatan persaingan tersebut, manajemen harus menentukan kebijakan yang tepat dalam usaha menarik tamu hotel dan berupaya untuk memenuhi tujuannya yaitu memperoleh keuntungan agar hotel dapat terus berkembang.

Untuk mengoptimalkan kebijakan yang akan diambil tersebut, salah satu caranya adalah pihak manajemen hotel harus memiliki kemampuan untuk meramalkan jumlah permintaan terhadap kamar hotel pada periode mendatang.

Adapun permasalahan hotel Bestskip Palembang yang menjadi studi kasus dalam penelitian ini adalah kesulitan dalam meramalkan jumlah permintaan terhadap kamar hotel. Karena kesalahan dalam meramalkan jumlah permintaan terhadap kamar hotel dapat berakibat ketidakefisiensian operasional hotel dan kesiapan pelayanan terhadap tamu yang akan menginap.

Oleh karena itu, pada penelitian ini akan dilakukan analisis kuantitatif yang berfokus pada pemilihan metode peramalan yang paling baik dalam pengelolaan permintaan kamar (demand management) sebagai salah satu dasar bagi pihak manajemen hotel dalam pengambilan keputusan (Gustriansyah 2016; Gustriansyah, Sensuse, and Ramadhan 2015) sehingga efisiensi operasional hotel dan kesiapan pelayanan terhadap tamu yang akan menginap dapat ditingkatkan, serta perencanaan budget keuangan hotel menjadi lebih efektif.

\section{Pembahasan}

Grafik dari pola data permintaan jumlah kamar hotel dari bulan Januari hingga November 2018 dapat dilihat pada Gambar 1. Pola data fluktuatif seperti ini lebih cocok menggunakan metode exponential smoothing (Gustriansyah 2017).

Penelitian ini akan meramalkan jumlah permintaan kamar hotel tipe standar menggunakan metode Exponential Smoothing dikomparasi dengan metode Regresi Linier dan Moving Average.

Metode yang memiliki tingkat akurasi yang tertinggi merupakan metode peramalan yang terbaik. Oleh karena itu akan dihitung tingkat kesalahan peramalan pada setiap metode peramalan, agar dapat diperoleh tingkat akurasinya. Semakin kecil tingkat kesalahan peramalan yang diperoleh, maka semakin tinggi akurasi metode peramalan tersebut (Gustriansyah 2017).

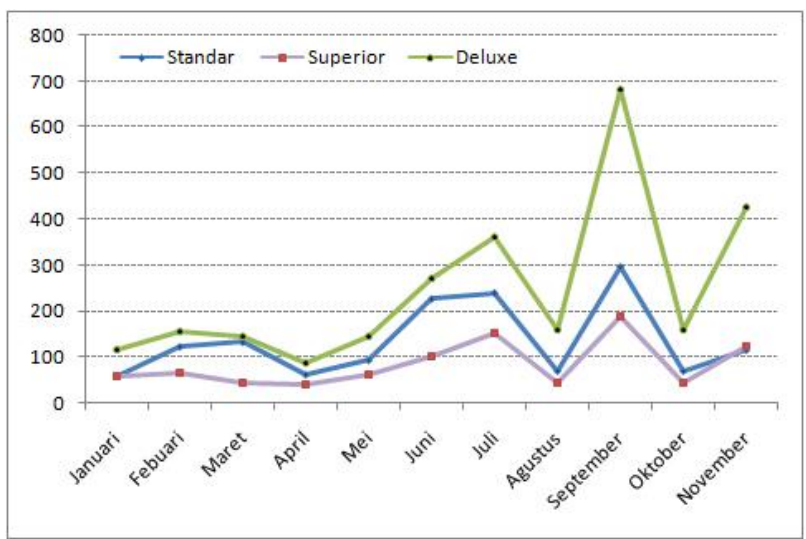

Gambar 1. Pola Data Jumlah Permintaan Kamar Hotel

Data yang digunakan dalam penelitian ini berupa jumlah permintaan kamar hotel Bestskip Palembang perbulan pada tahun 2018 (lihat Tabel 1).

Tabel 1. Jumlah Permintaan Kamar Hotel

\begin{tabular}{|c|c|c|c|}
\hline Bulan & Standar & Superior & Deluxe \\
\hline Januari & 60 & 57 & 117 \\
\hline Febuari & 123 & 64 & 158 \\
\hline Maret & 133 & 45 & 147 \\
\hline April & 63 & 40 & 88 \\
\hline Mei & 94 & 61 & 144 \\
\hline Juni & 226 & 102 & 273 \\
\hline Juli & 239 & 152 & 362 \\
\hline Agustus & 71 & 45 & 159 \\
\hline September & 295 & 188 & 683 \\
\hline Oktober & 71 & 45 & 159 \\
\hline November & 116 & 122 & 426 \\
\hline
\end{tabular}

Sumber: Hotel Bestskip Palembang (2018)

\section{A. Regresi Linier}

Regresi linier adalah alat statistik yang dipergunakan untuk mengetahui pengaruh antara satu atau beberapa variabel terhadap suatu variabel.

Persamaan umumnya adalah $\mathrm{Y}=\mathrm{a}+\mathrm{bX}$, dimana $\mathrm{Y}$ adalah variabel terikat (dependent), $\mathrm{X}$ adalah variabel bebas (independent), a adalah konstanta dan $\mathrm{b}$ adalah koefisien regresi (kemiringan) (Ohyver and Tanty 2012).

Nilai a dan $\mathrm{b}$ dihitung dengan menggunakan persamaan (1) dan (2).

$$
\begin{aligned}
& \mathrm{a}=\frac{\sum y \sum x^{2}-\sum x \sum x y}{\mathrm{n} \sum \mathrm{x}^{2}-\left(\sum x\right)^{2}} \\
& \mathrm{~b}=\frac{\mathrm{n} \sum \mathrm{x}-\sum \mathrm{x} \sum \mathrm{y}}{\mathrm{n} \sum \mathrm{x}^{2}-\left(\sum \mathrm{g}\right)^{2}}
\end{aligned}
$$

Adapun tahapan peramalan menggunakan metode Regresi Linier adalah sebagai berikut:

1) Identifikasi variabel bebas $(X)$ dan variabel terikat (Y);

2) Lakukan pengumpulan data;

3) Hitung $\mathrm{X}^{2}, \mathrm{Y}^{2}, \mathrm{XY}$ dan total dari masing-masingnya;

4) Hitung a dan $b$ berdasarkan persamaan (1) dan (2);

5) Buatkan Model Persamaan Regresi Linear Sederhana; 
6) Lakukan peramalan terhadap variabel bebas.

Pada penelitian ini ditentukan bulan sebagai variabel $\mathrm{X}$ dan jumlah permintaan kamar tipe standar sebagai variabel Y, seperti tertera pada Tabel 2.

Tabel 2. Perhitungan dengan Regresi Linier

\begin{tabular}{|c|c|c|c|c|c|}
\hline Bulan & $\mathbf{X}$ & $\mathbf{Y}$ & $\mathbf{X}^{\mathbf{2}}$ & $\mathbf{Y}^{\mathbf{2}}$ & $\mathbf{X Y}$ \\
\hline Jan & 1 & 60 & 1 & 3600 & 60 \\
\hline Feb & 2 & 123 & 4 & 15129 & 246 \\
\hline Mar & 3 & 133 & 9 & 17689 & 399 \\
\hline Apr & 4 & 63 & 16 & 3969 & 252 \\
\hline Mei & 5 & 94 & 25 & 8836 & 470 \\
\hline Jun & 6 & 226 & 36 & 51076 & 1356 \\
\hline Jul & 7 & 239 & 49 & 57121 & 1673 \\
\hline Ags & 8 & 71 & 64 & 5041 & 568 \\
\hline Sep & 9 & 295 & 81 & 87025 & 2655 \\
\hline Okt & 10 & 71 & 100 & 5041 & 710 \\
\hline Nov & 11 & 116 & 121 & 13456 & 1276 \\
\hline$\Sigma$ & 66 & 1491 & 506 & 267983 & 9665 \\
\hline
\end{tabular}

Selanjutnya dihitung nilai a dan $b$ dengan menggunakan persamaan (1) dan (2) sebagai berikut:

$$
\begin{aligned}
& \mathrm{a}=\frac{\left.\sum y \sum x^{2}-\sum x \sum x y\right)}{\mathrm{n} \sum \mathrm{x}^{2}-\left(T x^{2}\right)^{2}}=\frac{1491(506)-66(9665)}{11(506)-66^{2}}=96,3272
\end{aligned}
$$

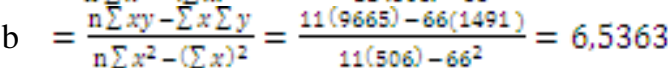

Sehingga model persamaan regresi linier menjadi: $\mathrm{Y}=96,3+6,5 \mathrm{X}$

Hasil peramalan jumlah permintaan kamar hotel menggunakan persamaan regresi linier dapat dilihat pada Gambar 2.

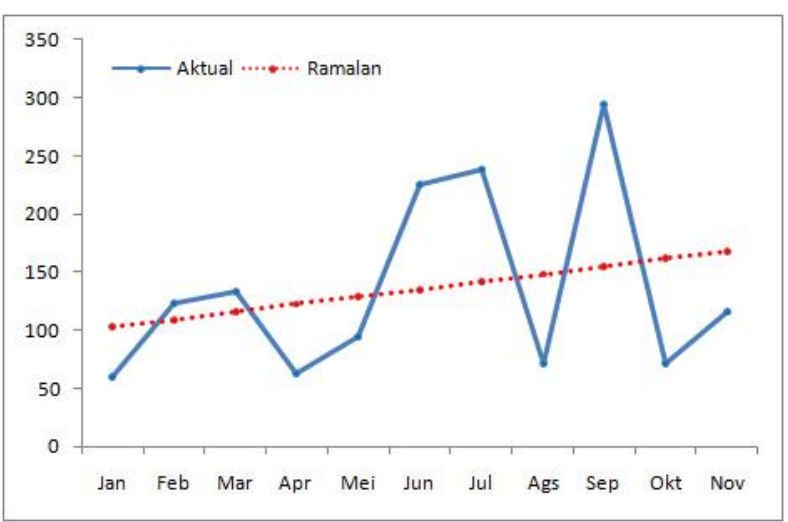

Gambar 2. Hasil Peramalan dengan Regresi Linier

Kesalahan peramalan jumlah permintaan kamar hotel pada penelitian ini dihitung dengan menggunakan Mean Absolute Percentage Error (MAPE). MAPE menyatakan rata-rata persentase kesalahan absolut dari hasil peramalan dengan menggunakan persamaan (3) (Nau 2014).

MAPE $=\frac{100}{\mathrm{~g}} \approx \frac{\sum\left|A_{\mathrm{E}}-F_{\mathrm{E}}\right|}{A_{\mathrm{E}}}$

dimana:

$A_{t}=$ data aktual pada periode ke $\mathrm{t}$
$F_{t}=$ data ramalan pada periode ke $\mathrm{t}$

$n$ = banyak periode waktu

Jika $\left|A_{t}-F_{t}\right|=|e|$, maka hasil perhitungan persentase kesalahan peramalan (MAPE) untuk metode regresi linier dapat dilihat pada Tabel 3.

Tabel 3. Perhitungan MAPE untuk Regresi Linier

\begin{tabular}{|c|c|c|c|c|}
\hline Bulan & $\mathbf{A}$ & $\mathbf{F}$ & e & $\%$ e \\
\hline Jan & 60 & 102,9 & 42,9 & 41,67 \\
\hline $\mathrm{Feb}$ & 123 & 109,4 & 13,6 & 12,43 \\
\hline Mar & 133 & 115,9 & 17,1 & 14,72 \\
\hline Apr & 63 & 122,5 & 59,5 & 48,56 \\
\hline Mei & 94 & 129,0 & 35,0 & 27,14 \\
\hline Jun & 226 & 135,5 & 90,5 & 66,73 \\
\hline Jul & 239 & 142,1 & 96,9 & 68,21 \\
\hline Ags & 71 & 148,6 & 77,6 & 52,23 \\
\hline Sep & 295 & 155,2 & 139,8 & 90,13 \\
\hline Okt & 71 & 161,7 & 90,7 & 56,09 \\
\hline Nov & 116 & 168,2 & 52,2 & 31,05 \\
\hline \multicolumn{3}{|c|}{$\sum$} & 715,8 & 508,96 \\
\hline & $\mathrm{n}=11$ & & \multicolumn{2}{|c|}{ MAPE $=46,3 \%$} \\
\hline
\end{tabular}

B. Single Moving Average (SMA)

Single moving average adalah suatu metode peramalan yang menggunakan rata-rata periode terakhir data untuk meramalkan periode berikutnya. Model moving average menggunakan sejumlah data aktual permintaan yang baru untuk membangkitkan nilai ramalan untuk permintaan di masa yang akan datang. Metode moving average akan efektif diterapkan apabila permintaan pasar terhadap produk diasumsikan stabil sepanjang waktu.

Untuk mendapatkan hasil ramalan pada periode mendatang diperlukan data historis selama jangka waktu tertentu. Misalnya dengan metode 3 bulan moving average, ramalan bulan ke-4 baru dapat dihitung setelah bulan ke-3 berakhir, dan demikian seterusnya (Nau 2014).

Metode ini akan efektif diterapkan jika diasumsikan bahwa data ramalan relatif stabil sepanjang periode.

Persamaan umumnya seperti pada persamaan (4) (Nau 2014):

$S_{t}^{\delta}=F_{t+1}=\frac{A_{\mathrm{L}}+A_{\mathrm{t}-1}+A_{\mathrm{t}-2}+\cdots+A_{\mathrm{t}-\mathrm{n}+1}}{n}$

dimana:

$S^{\prime}{ }_{t}=$ Moving Average untuk periode ke t

$F_{t+1}=$ Ramalan untuk periode $\mathrm{ke} \mathrm{t}+1$

$A_{t}=$ Data aktual untuk periode ke $\mathrm{t}$

$n$ = Periode waktu rata-rata bergerak

Hasil peramalan jumlah permintaan kamar hotel dengan menerapkan metode $S M A$ dapat dilihat pada Gambar 3. 


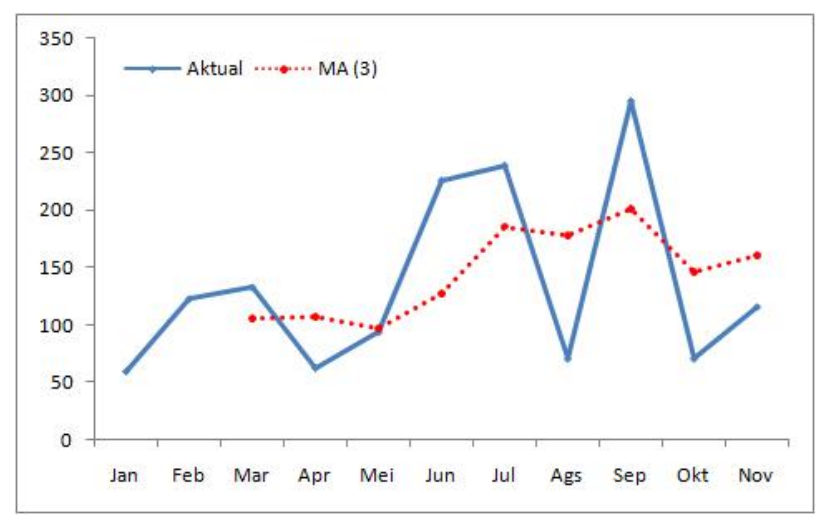

Gambar 3. Hasil Peramalan dengan SMA

Persentase kesalahan peramalan (MAPE) untuk metode SMA dapat dihitung menggunakan persamaan (3), seperti yang tertera pada Tabel 4.

Tabel 4. Perhitungan MAPE untuk SMA

\begin{tabular}{|c|c|c|c|c|}
\hline Bulan & $\mathbf{A}$ & SMA (3) & e & $|\% \mathrm{e}|$ \\
\hline Jan & 60 & - & - & - \\
\hline $\mathrm{Feb}$ & 123 & - & - & - \\
\hline Mar & 133 & 105,3 & 27,67 & 20,80 \\
\hline Apr & 63 & 106,3 & 43,33 & 68,78 \\
\hline Mei & 94 & 96,67 & 2,67 & 2,84 \\
\hline Jun & 226 & 127,7 & 98,33 & 43,51 \\
\hline Jul & 239 & 186,3 & 52,67 & 22,04 \\
\hline Ags & 71 & 178,7 & 107,67 & 151,64 \\
\hline Sep & 295 & 201,7 & 93,33 & 31,64 \\
\hline Okt & 71 & 145,7 & 74,67 & 105,16 \\
\hline Nov & 116 & 160,7 & 44,67 & 38,51 \\
\hline \multicolumn{3}{|c|}{$\sum$} & 545,00 & 484,92 \\
\hline \multicolumn{3}{|c|}{$\mathrm{n}=9$} & \multicolumn{2}{|c|}{ MAPE $=53,88 \%$} \\
\hline
\end{tabular}

C. Double Moving Average (DMA)

Double moving average merupakan suatu metode peramalan yang menggunakan data SMA pada waktu tertentu dengan penyesuaian antara single moving average-double moving average serta penyesuaian trend.

Adapun tahapan peramalan menggunakan metode DMA sebagai berikut (Azizah 2015):

1) Menghitung SMA:

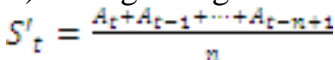

2) Menghitung DMA:

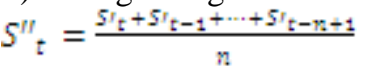

3) Menentukan nilai konstanta

$a_{t}=S_{t}^{t}+\left(S_{t}^{t}-S_{t}^{s t}\right)$

4) Menentukan slope

$b_{t}=\frac{2}{n-1}\left(S_{t}^{0}-S_{t}^{s t}\right)$

5) Melakukan peramalan

$F_{t+m}=a_{t}+b_{t m}$

$m$ adalah periode ramalan mendatang

Dengan menggunakan persamaan (5)-(9) diperoleh hasil perhitungan dengan metode $D M A$ seperti yang tertera pada Tabel 5 .
Tabel 5. Perhitungan dengan DMA

\begin{tabular}{|c|c|c|c|c|c|c|}
\hline Bulan & A & MA'(3) $^{\prime}$ & MA”(3) & a & b & F \\
\hline Jan & 60 & - & - & - & - & - \\
\hline Feb & 123 & - & - & - & - & - \\
\hline Mar & 133 & 105,3 & - & - & - & - \\
\hline Apr & 63 & 106,3 & - & - & - & - \\
\hline Mei & 94 & 96,67 & 102,8 & 90,6 & $-6,1$ & - \\
\hline Jun & 226 & 127,7 & 110,2 & 145,1 & 17,4 & 84,4 \\
\hline Jul & 239 & 186,3 & 136,9 & 235,8 & 49,4 & 162,6 \\
\hline Ags & 71 & 178,7 & 164,2 & 193,1 & 14,4 & 285,2 \\
\hline Sep & 295 & 201,7 & 188,9 & 214,4 & 12,8 & 207,6 \\
\hline & 71 & & & & - & \\
Okt & & 145,7 & 175,3 & 116,0 & 29,7 & 227,2 \\
\hline Nov & 116 & 160,7 & 169,3 & 152,0 & $-8,7$ & 86,3 \\
\hline
\end{tabular}

Hasil peramalan jumlah permintaan kamar hotel menggunakan metode DMA dapat dilihat pada Gambar 4.

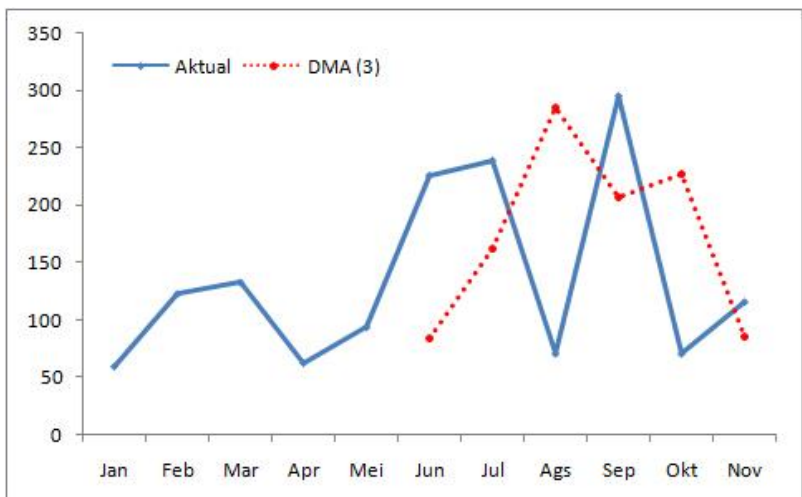

Gambar 4. Hasil Peramalan dengan DMA

Hasil perhitungan persentase kesalahan peramalan (MAPE) untuk metode DMA menggunakan persamaan (3) dapat dilihat pada Tabel 6.

Tabel 6. Perhitungan MAPE untuk DMA

\begin{tabular}{|c|c|c|c|c|}
\hline Bulan & $\mathbf{A}$ & DMA (3) & e & $\%$ e \\
\hline Jan & 60 & - & - & - \\
\hline Feb & 123 & - & - & - \\
\hline Mar & 133 & - & - & - \\
\hline Apr & 63 & - & - & - \\
\hline Mei & 94 & - & - & - \\
\hline Jun & 226 & 84,4 & 141,56 & 62,64 \\
\hline Jul & 239 & 162,6 & 76,44 & 31,99 \\
\hline Ags & 71 & 285,2 & 214,22 & 301,72 \\
\hline Sep & 295 & 207,6 & 87,44 & 29,64 \\
\hline Okt & 71 & 227,2 & 156,22 & 220,03 \\
\hline Nov & 116 & 86,3 & 29,67 & 25,57 \\
\hline \multicolumn{3}{|c|}{$\sum$} & 705,56 & 671,59 \\
\hline \multicolumn{3}{|c|}{$\mathrm{n}=6$} & \multicolumn{2}{|c|}{ MAPE $=111,93 \%$} \\
\hline
\end{tabular}

D. Single Exponential Smoothing (SES)

Metode $S E S$ atau penghalusan eksponensial tunggal adalah suatu prosedur yang secara terus menerus memperbaiki peramalan dengan merata-rata (menghaluskan) nilai masa lalu dari suatu data deret waktu dengan cara eksponensial (Gustriansyah 2017). 
Metode SES termasuk metode prediksi kuantitatif dengan pola data historis yang tidak stabil dan berdasarkan deret waktu.

Metode SES lebih cocok digunakan untuk meramalkan hal-hal yang fluktuasinya tidak teratur (acak) (Gustriansyah 2017).

Berikut persamaan metode SES seperti pada persamaan (10) (Nau 2014):

$F_{t+1}=\alpha A_{t}+(1-\alpha) F_{t}$

Keterangan:

$F_{t}=$ Nilai ramalan periode $\mathrm{t}$ (sebelumnya)

$F_{t+1}=$ Nilai ramalan periode $\mathrm{t}+1$ (berikutnya)

$A_{t}=$ Nilai aktual periode $\mathrm{t}$

$\alpha=$ Konstanta smoothing $(0<\alpha<1)$. Nilai terbaik untuk $\alpha$ adalah yang menghasilkan kesalahan ramalan rata-rata terkecil. Pada penelitian ini, konstanta $\alpha=0,1$ menghasilkan kesalahan ramalan rata-rata terkecil dengan nilai ramalan awal $=60$ (bulan Januari).

Hasil peramalan jumlah permintaan kamar hotel yang menggunakan metode SES dapat dilihat pada Gambar 5.

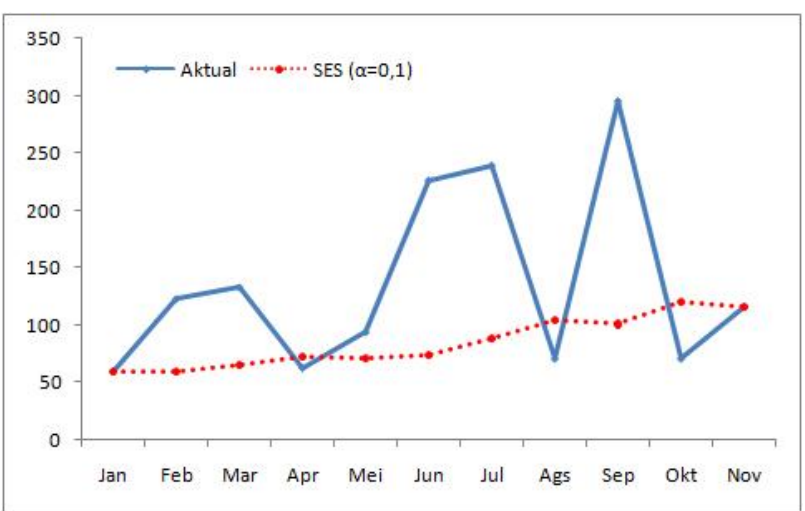

Gambar 5. Hasil Peramalan dengan SES

Hasil perhitungan kesalahan peramalan menggunakan MAPE untuk metode SES dapat dilihat pada Tabel 7 .

Tabel 7. Perhitungan MAPE untuk SES

\begin{tabular}{|c|c|c|c|c|}
\hline Bulan & $\mathbf{A}$ & SES $(\alpha=0,1)$ & e & $\mid \%$ e $\mid$ \\
\hline Jan & 60 & 60,0 & - & - \\
\hline Feb & 123 & 60,0 & 63,00 & 51,22 \\
\hline Mar & 133 & 66,3 & 66,70 & 50,15 \\
\hline Apr & 63 & 73,0 & 9,97 & 15,83 \\
\hline Mei & 94 & 72,0 & 22,03 & 23,43 \\
\hline Jun & 226 & 74,2 & 151,82 & 67,18 \\
\hline Jul & 239 & 89,4 & 149,64 & 62,61 \\
\hline Ags & 71 & 104,3 & 33,32 & 46,93 \\
\hline Sep & 295 & 101,0 & 194,01 & 65,77 \\
\hline Okt & 71 & 120,4 & 49,39 & 69,56 \\
\hline Nov & 116 & 115,5 & 0,55 & 0,47 \\
\hline \multicolumn{3}{|c|}{$\sum$} & 740,43 & 453,16 \\
\hline \multicolumn{3}{|c|}{$\mathrm{n}=11$} & \multicolumn{2}{|c|}{ MAPE $=41,20 \%$} \\
\hline
\end{tabular}

E. Double Exponential Smoothing (DES)

Metode DES merupakan salah satu jenis dari metode Exponential Smoothing yang digunakan ketika plot data berbentuk tren (Gustriansyah 2017).
Adapun tahapan peramalan menggunakan metode DES adalah sebagai berikut (Gustriansyah 2017):

1) Menghitung $S E S$ :

$S_{t}{ }_{t}=a A_{t}+(1-\alpha) S^{\prime}{ }_{t-1}$

2) Menghitung $D E S$ :

$S^{\prime}{ }_{t}=a S^{\prime}{ }_{t}+(1-\alpha) S^{\prime \prime}{ }_{t-1}$

3) Menentukan konstanta

$a_{t}=2 S^{\prime}{ }_{t}-S^{\prime}{ }_{t} \quad$ (12)

4) Menentukan slope:

$b_{t}=\frac{x}{1-x}\left(S^{s}-S^{s t}\right)$

5) Melakukan peramalan

$F_{t+m}=a_{t}+b_{t m} \quad$ (14)

$m$ adalah periode ramalan mendatang

Dengan menggunakan persamaan (10)-(14) diperoleh hasil perhitungan dengan metode $D E S$ seperti yang tertera pada Tabel 8 .

Tabel 8. Perhitungan dengan metode DES $(\alpha=0,1)$

\begin{tabular}{|c|c|c|c|c|c|c|}
\hline Bulan & A & ES & ES $^{\prime \prime}$ & a & b & F \\
\hline Jan & 60 & 60,0 & 60,0 & 60,0 & 0,0 & 60,0 \\
\hline Feb & 123 & 60,0 & 60,0 & 60,0 & 0,0 & 60,0 \\
\hline Mar & 133 & 66,3 & 60,6 & 72,0 & 0,6 & 72,6 \\
\hline Apr & 63 & 73,0 & 61,9 & 84,1 & 1,2 & 85,3 \\
\hline Mei & 94 & 72,0 & 62,9 & 81,1 & 1,0 & 82,1 \\
\hline Jun & 226 & 74,2 & 64,0 & 84,3 & 1,1 & 85,5 \\
\hline Jul & 239 & 89,4 & 66,5 & 112,2 & 2,5 & 114,7 \\
\hline Ags & 71 & 104,3 & 70,3 & 138,3 & 3,8 & 142,1 \\
\hline Sep & 295 & 101,0 & 73,4 & 128,6 & 3,1 & 131,7 \\
\hline Okt & 71 & 120,4 & 78,1 & 162,7 & 4,7 & 167,4 \\
\hline Nov & 116 & 115,5 & 81,8 & 149,1 & 3,7 & 152,8 \\
\hline
\end{tabular}

Hasil peramalan jumlah permintaan kamar hotel menggunakan metode $D E S$ ini dapat juga dilihat pada Gambar 6. Perhitungan DES menggunakan konstanta $\alpha=0,1$ karena menghasilkan kesalahan ramalan rata-rata terkecil dibandingkan dengan nilai $\alpha$ yang lain.

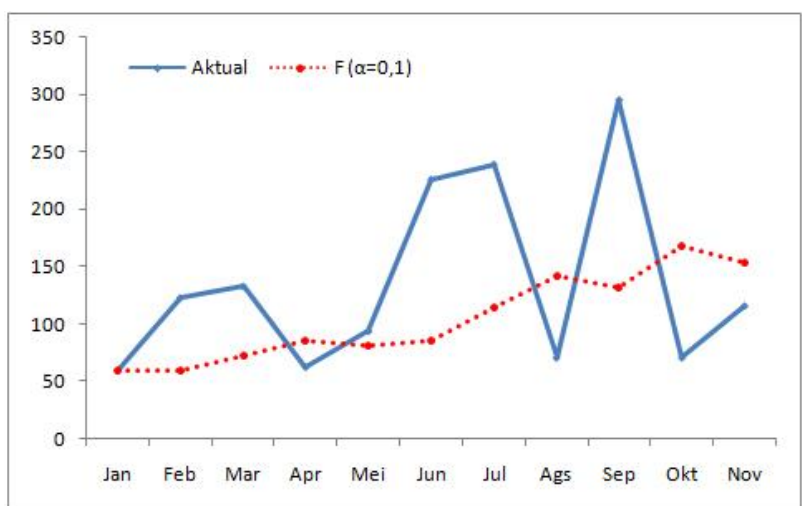

Gambar 6. Hasil Peramalan dengan DES

Adapun hasil perhitungan persentase kesalahan peramalan (MAPE) untuk metode DES dapat dilihat pada Tabel 9.

Tabel 9. Perhitungan MAPE untuk DES

\begin{tabular}{|c|c|c|c|c|}
\hline Bulan & A & DES (a=0,1) & $|\mathbf{e}|$ & $\mid \boldsymbol{\%}$ e $\mid$ \\
\hline Jan & 60 & 60,0 & 0,00 & 0,00 \\
\hline
\end{tabular}




\begin{tabular}{|c|c|c|c|c|}
\hline Bulan & $\mathbf{A}$ & $\operatorname{DES}(\alpha=0,1)$ & e & |\% e \\
\hline Feb & 123 & 60,0 & 63,00 & 51,22 \\
\hline Mar & 133 & 72,6 & 60,40 & 45,41 \\
\hline Apr & 63 & 85,3 & 22,31 & 35,41 \\
\hline Mei & 94 & 82,1 & 11,92 & 12,68 \\
\hline Jun & 226 & 85,5 & 140,52 & 62,18 \\
\hline Jul & 239 & 114,7 & 124,29 & 52,00 \\
\hline Ags & 71 & 142,1 & 71,10 & 100,15 \\
\hline Sep & 295 & 131,7 & 163,34 & 55,37 \\
\hline Okt & 71 & 167,4 & 96,40 & 135,77 \\
\hline Nov & 116 & 152,8 & 36,82 & 31,74 \\
\hline \multicolumn{3}{|c|}{$\sum$} & 790,10 & 581,93 \\
\hline & & & \multicolumn{2}{|c|}{ MAPE $=52,90 \%$} \\
\hline
\end{tabular}

Perbandingan hasil perhitungan persentase kesalahan peramalan (MAPE) untuk metode regresi linier, SMA, DMA. SES, dan DES dapat dilihat pada Gambar 7.

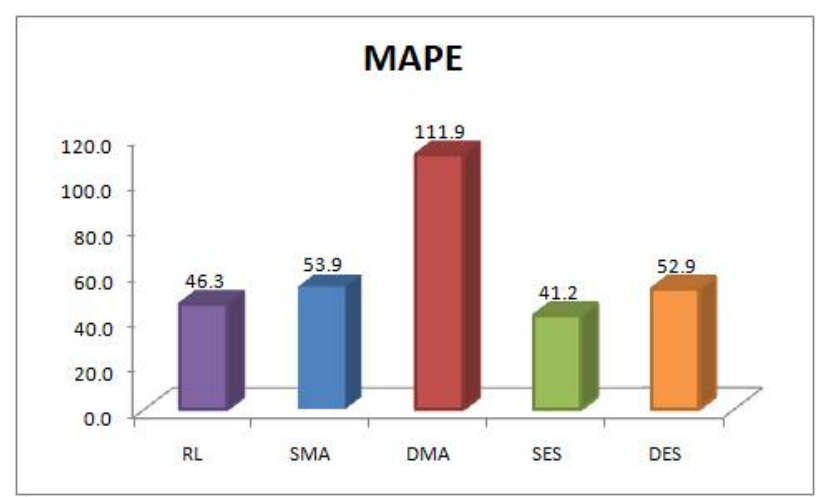

Gambar 7. MAPE untuk Setiap Metode Peramalan

Hasil perhitungan pada Gambar 7 menunjukkan bahwa peramalan jumlah permintaan kamar hotel menggunakan metode SES memiliki nilai MAPE terkecil $(41.2 \%)$. Ini berarti bahwa peramalan jumlah permintaan kamar hotel untuk pola data seperti pada penelitian ini, metode SES merupakan metode yang memiliki akurasi paling baik.

\section{Kesimpulan dan Saran}

Hasil penelitian ini menunjukan bahwa persentase kesalahan peramalan jumlah permintaan kamar hotel dengan metode Single Exponential Smoothing (MAPE $=41,2 \%)$ lebih rendah dibandingkan dengan persentase kesalahan peramalan dengan metode Regresi Linier, Single Moving Average (SMA), Double Moving Average (DMA), Single Exponential Smoothing (SES) dan Double Exponential Smoothing (DES), sehingga menunjukkan bahwa metode SES mempunyai akurasi peramalan yang lebih baik dibandingkan dengan metode yang lain.

Hasil penelitian ini dapat memberikan konstribusi pada pengembangan sistem peramalan permintaan jumlah kamar hotel dan sebagai referensi pendukung dalam pengembangan toolkit (Sanmorino et al. 2017) untuk mempermudah aktivitas peramalan.

\section{Daftar Pustaka}

Azizah, Auli Fisty Noor. 2015. "Peramalan Migrasi Masuk Kota Surabaya Tahun 2015 Dengan Metode Double Moving Average Dan Double Exponential Smoothing Brown." Jurnal Biometrika Dan Kependudukan 4 (2): 172-80.

Gustriansyah, Rendra. 2016. "Sistem Pendukung Keputusan Pemilihan Dosen Berprestasi Dengan Metode ANP Dan TOPSIS." In Seminar Nasional Teknologi Informasi Dan Komunikasi (SENTIKA), 33-40. Yogyakarta: UAJY.

- 2017. "Analisis Metode Single Exponential Smoothing Dengan Brown Exponential Smoothing Pada Studi Kasus Memprediksi Kuantiti Penjualan Produk Farmasi Di Apotek." In Seminar Nasional Teknologi Informasi \& Multimedia, 6-11. Yogyakarta.

http://ojs.amikom.ac.id/index.php/semnasteknomed ia/article/view/1653.

Gustriansyah, Rendra, Dana Indra Sensuse, and Arief Ramadhan. 2015. "Decision Support System for Inventory Management in Pharmacy Using Fuzzy Analytic Hierarchy Process and Sequential Pattern Analysis Approach." In 2015 3rd International Conference on New Media (CONMEDIA), 1-6. IEEE. https://doi.org/10.1109/CONMEDIA.2015.744915. Menteri Pariwisata, Pos dan Telekomunikasi. 1986. "Peraturan Usaha Dan Penggolongan Hotel (Keputusan Menteri Pariwisata, Pos Dan Telekomunikasi No. KM.37/PW.304/MPPT-86)."

Nau, Robert. 2014. "Averaging and Exponential Smoothing Models." http://people.duke.edu/ rnau/notes_on_forecasting _with_moving_averages--robert_nau.pdf.

Ohyver, Margaretha, and Heruna Tanty. 2012. "Pendeteksian Outlier Pada Model Regresi Ganda: Studi Kasus Tingkat Penghunian Kamar Hotel Di Kendari." MatStat 12 (2): 114-22.

Sanmorino, A., R. Gustriansyah, Terttiaavini, and Isabella. 2017. "The Toolkit of Success Rate Calculation of Broiler Harvest." Telkomnika (Telecommunication Computing Electronics and Control) 15 https://doi.org/10.12928/TELKOMNIKA.v15i4.67 44. 